\title{
Family-Friendly Workplace Policies as Predictors of Sustainable Workforce in the Service Industry in Lagos State, Nigeria
}

\author{
A.F. Afonja \\ University of Lagos, Nigeria
}

This paper examined family-friendly policies as predictors of committed/sustainable workforce in service industry. Using a descriptive survey research design, 440 participants were randomly selected for the study. Findings revealed that there is a relationship between family friendly policies and committed/ sustainable workforce in both private and public service organizations in Lagos State, Nigeria and that there is a difference in the family friendly policies of private and public institutions in Lagos State with the private institution recording higher mean score. The study recommended among others that there should be harmonization of family friendly policies in the private and public institutions.

\section{INTRODUCTION}

One of the aims of an employer in setting up an organization is for the firm to stand the test of time and outlive him/her. Similarly, an employee looks for firms/organizations with the culture of sustainability to work for. To this end, a sustainable/committed workforce is crucial to the long term viability of an organization. Having competitive advantage and staying viable depend on healthy and committed employees. For an organization to have a sustainable and committed workforce, such organization has to put in place policies that will take care of the needs of employees both in and outside of the work. Family friendly polices aim to help employees manage their family responsibilities, create flexible work conditions and enable them to perform better on both domestic and work fronts. These policies known as Family Friendly Policies (FFPs) see to the general work environment in such a way that employees' needs for work-life balance are met. This implies that these FFPs must be embedded in the culture of the organization to ensure that employees' work environment is less stressful, and commitment to the general wellbeing of the employees' is given high priority.

Workforce sustainability is about bringing together and retaining the right people, with the right skills and capabilities to meet requirements of the organization. It also means having employees with low turnover and high commitment level so that they are able to deliver to customers. Attracting and retaining employees require that organizations value and respect their employees and their families, and also make work environment flexible. According to Kosseck, Valcour \& Lino (2014), a sustainable/committed workforce is one where the work environment is caring and supports employees' wellbeing. Employees are not seen as primary resources that can be deployed and depleted to serve employers' economic ends. Employees are treated like customers in which workplace options are flexible enough to meet the needs and changing circumstances are offered. In fact, the first customers of an organization are its employees and they should be accorded the respect and treatment offered to all customers. 
A sustainable workforce is created and nurtured when the workplace is such that employment practices are linked to employees' work-life balance and wellbeing; to employee employment experiences over the course of their working lives, enabling them to perform well over time while also thriving in their personal and family lives. This makes McDonald, Bradley and Brown (2009), to opine that sustainable work practices equip individuals and families with economic resources and opportunities for professional and personal growth, in an atmosphere that allows workers to attend to interests and responsibilities inside and outside of work. When work practices make employees happy and fulfilled, they not only survive but thrive. Ruderman, Ohlott, Pranzel and King (2002) in their study reviewed that employees who have happy personal lives bring skills and positive energies from home to work.

The service industry in Nigeria is very important to the economy of the state. It no doubt plays a vital role in the Gross Domestic Product (GDP) of the nation. Hence, having a sustainable and well committed workforce is very germane not only to the industry but also to the nation as well. The service industry, be it communication, education, health or finance cannot afford to have frequent turn- over of employees because as much as possible, stability is needed. It is for this and many other reasons that family friendly policies are part of the organizational culture and values which are applied from top to bottom in the hierarchy of the organization. A well applied culture and values bring about commitment and sustainability of employees/workforce.

A lot has been done and said about sustainability of environmental resources, economic sustainability thus making Pfeffer (2010) to say that just as there is growing concern about promoting the sustainability of environmental resources, there should be similar concern for fostering the sustainability of human resources. However, the sustainability of people, their work-life balance and wellbeing has been undervalued relative to other target of sustainability, Ehnert (2009) lamented. It is therefore, the concern of this study to investigate how family friendly policies of private and public organizations have helped in the sustainability/commitment of the workforce in service industry in Lagos State, Nigeria.

\section{STATEMENT OF THE PROBLEM}

A sustainable workforce is crucial to long-term viability of a business and especially to the service industry that plays a vital role in the economy of a nation like Nigeria. Unfortunately, few of these organizations seem to understand this. Treating and valuing employees as assets to be nurtured is very germane to the sustainability of the workforce but only few firms have truly embraced the creation of a sustainable/committed workforce due to high level turn over. Also, literature abounds on environmental sustainability, economic sustainability and societal sustainability while little is known about workforce sustainability especially in developing countries like Nigeria. A happy workforce brings about a happy nation. Thus, this work seeks to examine if family-friendly workplace policies will bring about committed/sustainable workforce in the service industry.

\section{PURPOSE OF THE STUDY}

The main purpose of the study was to examine organizations family-friendly policies as predictors of committed/sustainable workforce in the service industry in Lagos State, Nigeria. Specifically, the study seeks to:

1. identify various family friendly policies that are put in place in both private and public organizations operating in the service industry;

2. establish if there is a relationship between family friendly policies of both private and public service organizations and sustainable/committed workforce; and

3. determine if there is a difference in the family friendly policies of private and public organizations operating in the service industry. 


\section{RESEARCH HYPOTHESES}

Two hypotheses were developed to the guide the study.

(i) Organization's family friendly policies will not significantly predict workforce sustainability/ commitment in the service industry.

(ii) There is no significant difference in the family friendly policies of private and public organizations operating in the service industry

\section{METHODOLOGY}

The study adopted a descriptive research designs. The population for the study includes all full time employees in both private and public organizations operating in the service industry in Lagos State, Nigeria. A multistage sampling procedure involving stratified random sampling technique was used to select the respondents for the study. A total of four hundred and eighty (480) respondents formed the sample for the study. The main instrument for data collection was a questionnaire titled: family friendly policies and committed/sustainability of workforce Questionnaire (FFPCSWQ). The instrument had two sections. Section A has the demographic characteristics of the respondents such as gender, age, experience, employment status among others while section B has two Parts- Part I and II covering the key variables of the study. Part I comprised 30 items covering 5 dimension of workplace family Policies. The items were rated in modified four point Likert scale such as Strongly Agree (4), Agree (3), Disagree (2) and Strongly Disagree (1), while part II covered the 10 item statements on Committed/Sustainable workforce. The content and face validity of the instrument was carried out by experts in the field of adult education, psychology and test and measurement. To establish the reliability of the instrument, a pilot study was conducted on 40 respondents (20 from private and 20 from public organizations) using testretest method. Pearson Product Moment correlation test of reliability was applied at alpha level of 0.05 using Statistical Package for Social Sciences (SPSS) software. The result yielded an alpha co-efficient of 0.869 high enough to justify the adoption of the instrument in the main study. The results of the analysis were presented as mean and standard deviation while the hypotheses were tested using inferential statistics- independent t-test, multiple regression and ANOVA.

\section{RESULTS PRESENTATION}

TABLE 1

\section{DESCRIPTIVE STATISTICS \& CORRELATION MATRIX OF FAMILY FRIENDLY POLICIES AND SUSTAINABILITY/COMMITMENT OF WORKFORCE $(\mathrm{N}=440)$}

\begin{tabular}{|l|l|l|l|l|l|l|l|l|l|}
\hline Variable & Mean & $\begin{array}{l}\text { Std. } \\
\text { Dev. }\end{array}$ & 1 & 2 & 3 & 4 & 5 & 6 & 7 \\
\hline SWF & 2.32 & .434 & 1 & & & & & & \\
\hline PL & 2.54 & .506 & -.119 & 1 & & & & & \\
\hline JS & 2.67 & .447 & .170 & .115 & 1 & & & & \\
\hline WH & 2.66 & .542 & $-.297^{*}$ & .077 & .111 & 1 & & & \\
\hline WCS & 2.54 & .534 & $.167^{* *}$ & $.612^{*}$ & $.233^{* *}$ & .122 & 1 & & \\
\hline FW & 2.49 & .530 & $.199^{* *}$ & .069 & $.209^{* *}$ & $.301^{* *}$ & $.261^{* *}$ & 1 & \\
\hline FI & 2.67 & .546 & $.496^{* *}$ & $.543^{* *}$ & $.361^{* *}$ & $.352^{* *}$ & $.393^{* *}$ & $.2201^{* *}$ & 1 \\
\hline
\end{tabular}

** Correlation is significant at 0.01 level (2-tailed)

- Correlation is significant at 0.05 level (2-tailled)

Keys: SWF (Sustainable workforce), PL (Parental Leave), JS (Job Sharing), WH (Working from home), WCH (Workplace Child Support/Care), FW (Flexible work time), FI (Family Insurance) 
Table 1 shows the mean values, standard deviation, and correlation matrix among the studied variables. All correlations are significant at $p<.01$. From the table, it is evident that sustainable workforce recorded a mean value (2.32), Parental leave (2.54), job sharing has a mean of 2.67, working at from home during normal working hours (2.66), workplace child support/child care (2.49), flexible work time policy (2.88), and family insurance policy (2.67). The standard deviation for each variable ranges from 0.434 to 0.546 indicating that responses on each variable were not widely spread out. Similarly, the result from the table also suggest that there is a statistically significant correlation between sustainable workforce and workplace parental leave policy since $\mathrm{r}=.496^{*}, \mathrm{p}<.01$, sustainable workforce and workplace job sharing policy $\left(.543^{* *}\right)$, sustainable workforce and workplace working from home policy $\left(.361^{* *}\right)$, sustainable workforce and workplace child support/care (.352**), sustainable workforce and flexible work time $\left(.329^{* *}\right)$ and finally, sustainable workforce and family insurance policy $\left(.2201^{* *}\right)$.

TABLE 2

\section{REGRESSION SUMMARY SHOWING RELATIONSHIP OF FAMILY-FRIENDLY WORKPLACE POLICIES AND COMMITTED/SUSTAINABLE WORKFORCE}

\begin{tabular}{|c|c|c|c|c|}
\hline Model & $\mathrm{R}$ & R Square & $\begin{array}{c}\text { Adjusted R } \\
\text { Square }\end{array}$ & Std. Error of the Estimate \\
\hline 1 & $.636(a)$ & .442 & .475 & .52199 \\
\hline
\end{tabular}

a. Predictors: (Constant) SWF (Sustainable workforce), PL (Parental Leave), JS (Job Sharing), WH (Working at home), WCH (Workplace Child Support/Care), FW (Flexible work time), FI (Family Insurance)

Table 2 shows the results of the relationships between family-friendly workplace policies as correlate of sustainable workforce in work places. The results demonstrate a robust level of fit $\left(R=.636, R^{2}=\right.$. 442). This indicates that there is a good fit between the regression model and the data; that is, the model is valid to predict the relationship between family friendly policies and committed/workforce since the predictor variable accounts for $44.2 \%$ of the variation in sustainable workforce. To confirm if the result of Multiple Regressions was significant, Analysis of Variance (ANOVA) was carried out and the result is presented in Table 3.

TABLE 3

ONE WAY ANALYSIS OF VARIANCE (ANOVA) SHOWING RELATIONSHIP BETWEEN FAMILY-FRIENDLY WORKPLACE POLICIES AND SUSTAINABLE WORKFORCE

\begin{tabular}{lcccccr}
\hline Model & $\begin{array}{c}\text { Sum of } \\
\text { Squares }\end{array}$ & Df & $\begin{array}{c}\text { Mean } \\
\text { Square }\end{array}$ & F & Sig. & Remark \\
\hline $1 \quad$ Regression & 108.120 & 6 & 16.316 & & & \\
& & & & 55.586 & $.000($ a) & Significant \\
$\quad$ Residual & 115.258 & 423 & .282 & & & \\
$\quad$ Total & $\mathbf{2 2 3 . 3 7 7}$ & $\mathbf{4 2 9}$ & & & & \\
\hline
\end{tabular}

a. Predictors: (Constant) PL (Parental Leave), JS (Job Sharing), WH (Working at home), WCH

(Workplace Child Support/Care), FW (Flexible work time), FI (Family Insurance)

b. Dependent Variable: Sustainable workforce

The results from the ANOVA table show that $\mathrm{F}_{\text {. }}$ statistics $=55.584$ is statistically significant at $\mathrm{p}=.000$ $<.05$ given $(\mathrm{df}=6,423)$. The null hypothesis which states that family friendly workplace policies (Parental Leave, Job Sharing, working at home, workplace child support/care, Flexible work time and 
Family Insurance) will not significantly predict committed/sustainable workforce was rejected. In other words, there is a statistically significant influence of family friendly workplace polices on employees commitment/sustainability. To establish the relative contribution of each indices of family friendly workplace polices on employee sustainable workforce, the relative $\beta$-values and corresponding p-values of all the sub-variables were established and results are presented in Table 4.

\section{TABLE 4 \\ RELATIVE CONTRIBUTION OF INDEPENDENT VARIABLES ON CRITERION (COMMITTED/SUSTAINABLE WORKFORCE) VARIABLE}

\begin{tabular}{|c|c|c|c|c|c|c|c|}
\hline \multirow[t]{2}{*}{ Model } & & \multicolumn{2}{|c|}{$\begin{array}{l}\text { Unstandardized } \\
\text { Coefficients }\end{array}$} & \multirow{2}{*}{$\begin{array}{c}\text { Standardized } \\
\text { Coefficients } \\
\text { B } \\
\end{array}$} & \multirow[b]{2}{*}{$\mathbf{t}$} & \multirow[b]{2}{*}{ Sig. } & \multirow[b]{2}{*}{ Remarks } \\
\hline & & B & Std. Error & & & & \\
\hline \multirow[t]{7}{*}{1} & (Constant) & .500 & .227 & & 2.201 & .008 & Significant \\
\hline & Parental Leave & .142 & .067 & .276 & 2.526 & .016 & Significant \\
\hline & Job Sharing & .146 & .063 & .279 & 2.612 & .015 & Significant \\
\hline & Working at home & .160 & .059 & .221 & 2.508 & .020 & Significant \\
\hline & $\begin{array}{l}\text { Workplace child } \\
\text { support }\end{array}$ & .086 & .050 & .289 & 3.939 & .000 & Significant \\
\hline & Flexible work time & .352 & .039 & .433 & 4.869 & .000 & Significant \\
\hline & Family insurance & .332 & .042 & .336 & 4.488 & .000 & Significant \\
\hline
\end{tabular}

a. Dependent Variable: Sustainable workforce

b. Predictors: (Constant) Parental Leave, Job Sharing, Working at home, Workplace Child Support/Care,

Flexible work time, Family Insurance

The result from Table 4 indicates that all the predictor variables were statistically significant with committed/sustainable workforce. Family insurance made the most significant contributions with $(\mathrm{t}=.4 .488, \mathrm{P}=.000>.05)$ while working from home $(\mathrm{t}=.2508, \mathrm{P}=.020>.05)$ made the least significant contributions to workforce sustainability/commitment. Other variables that made significant contributions include- Flexible work time $(\mathrm{t}=4.433, \mathrm{P}=.000<.05)$ workplace child support $(\mathrm{t}=3.939, \mathrm{P}=.000<.05)$, job sharing $(\mathrm{t}=2.612, \mathrm{P}=.015<.05)$ and parental leave $(\mathrm{t}=2.526, \mathrm{P}=.016<.05)$. The result implies that parental leave, job sharing, working from home, workplace child support/care, flexible work time, family insurance jointly account for the variance in workforce sustainability/commitment . In other word, there is a significant influence of workplace family friendly policies on sustainable/committed workforce in the service industry in Nigeria.

TABLE 5

DIFFERENCE IN WORKPLACE FAMILY-FRIENDLY POLICIES IN THE PUBLIC AND PRIVATE SECTOR

\begin{tabular}{lccccccc}
\hline & Variables & N & Mean & SD & Df & t-value & P-value \\
\hline \multirow{2}{*}{ FFP } & Public Sector & 210 & 1.546 & .2222 & \multirow{4}{*}{ 418 } & 2.987 & 0.003 \\
& Private Sector & 210 & 1.598 & .2296 & & & \\
\hline
\end{tabular}

Table 5 presents the t-test analysis of difference in workplace family-friendly policies in private and public sector of the Nigerian service industry. With respect to the mean score, the private sector recorded slightly higher mean score $(M=1.598, S . D=0.2296)$ against the public sector with a mean score of 
$(\mathrm{M}=1.546, \mathrm{~S} . \mathrm{D}=0.2222)$. The slight difference in the mean score was statistically significant as $\mathrm{t}-$ calculate $(\mathrm{t}-\mathrm{cal}=2.987)$ at $\mathrm{p}=0.003$ with 418 degree of freedom. From this result the null hypothesis was rejected.

\section{DISCUSSION OF FINDINGS}

Findings from the study showed that family friendly policies play a significant role on the sustainability/commitment of the workforce in the service industry. After controlling other determinants on the measure of sustainability/commitment of the workforce, the result revealed that all the familyfriendly policies variables used had a significant positive effect on commitment/sustainability of the workforce in the service industry. Parental leave, job sharing, working at home, workplace child support/care, flexible work time, family insurance all have positive relationship with sustainable/committed workforce. This is to say that employees who thought their employers offered parental leave (non-statutory), job share, flexible time, child support/care among the family friendly policies all tended to have high level of commitment and higher chances of staying back in the organization than employees who did not believe they were offered such arrangements. This is in line with the social exchange theory which shows that employees tend to feel obligated to reciprocate when they are provided with benefits (Prottas, Thompson, Kopelman \& Jahn, 2007). In other words, employees may perceive that FFPs are indicators of organizational supportiveness and try to be more committed to their companies in order to reciprocate FFPs given by their organizations. By so doing, this eventually leads to sustainable workforce in such organizations. This finding supports the work of Kosseck, Valcour and Lino (2014) in which they reported a significant association between job sharing, working from home, having a workplace nursery, emergency leave and employee level of job commitment. Accordingly, the author is of the view that employees in organizations where adequate attention were given to FFPs reported more commitment to their organizations leading to sustainable workforce. This finding calls for family-friendly policies and practices that address many of the current working arrangements in most service industries particularly in the public sector. A comprehensive policy approach to family friendly policies should include measures to ensure adequate implementation of parental leave, job sharing, working from home, workplace child support/care, flexible work time and family insurance. This, as observed by Brough and O'Driscoll (2010) is because without a genuine supportive workplace, the gap between policy and practice can be striking. A workplace that supports and assists with managing work-life balance may signal that the employer cares for employee wellbeing, leading to positive outcomes for the employee and the organization through increased loyalty, productivity and overall commitment. This finding calls for a new momentum that will help business leaders, HR executives to adopt a new approach in creating sustainable/committed workforce in service industry in Nigeria for the benefits of organization and the society at large.

Similarly, findings from hypothesis two also revealed a significant difference in family-friendly policies of the service industry in private and public sectors in Nigeria. While the public sector appears to be doing well in some key areas such as maternity leave, the same may not be attributed to the private sector. Family-friendly policies benefit employers, families, and society. This result is in tune with Adewale (2004) who also reported a significant difference in workplace family friendly policies. This calls for harmonization of family friendly policies in both private and public sectors in the service industry across Nigeria. Moreover, evidence from researches shows that harmonization of family friendly policies benefit employers, employees and society. Employers gain in employee retention, loyalty, and productivity; Employees gain by striking a balance between work and family obligations, reduced stress, and better quality of family life and life in general; while the society gains because family-friendly policies lead to more stable families with time to contribute to their communities and better outcomes for children. 


\section{RECOMMENDATIONS}

1. Employers of labour should provide more flexible work schedules, child care support, family leave options, job shifts and other family-friendly benefits to employees.

2. Government should consider creating and strengthening existing laws that support family friendly policies in the labour market. Laws such as maternity and paternity leave, protecting employees from long hours of work, realistic work life culture must be promoted amongst others.

3. Harmonization of family friendly policies in both the Public and Private sectors should be established and strict laws enforcing their implementation should also be put in place.

\section{CONCLUSION}

Family-friendly policies contribute to positive employees' sustainability. In Nigeria, provision of some of the family friendly policies are part of the organizational culture and values although the implementation of most workplace family friendly programmes are often put into question. This is due to employers non (commitment and poor compliance to the rules of such programmes, however the result from this study showed that family friendly policies such as insurance for employee family, parental leave, and Child support/care policy in public and private institutions are key policies that need to be implemented by employers of labour for more employees sustainability/commitment to the organization. This will reduce employee turn-over and little disruptions in provision of services to the populace in the service industry in Nigeria.

\section{REFERENCES}

Adewale, E. (2004). The impact of family-friendly policies in Nigeria on mothers' career interruptions due to childbirth. Journal of Vocational Behavior, 54, 392-415.

Brough, P. \& O'Driscoll, M.P. (2010). Organizational interventions for balancing work and home demands: An overview, Work and Stress, 24(3), 280-297.

Ehnert, I. (2009). Sustainable human resource management: A conceptual and exploratory analysis from a paradox perspective. Physical-Verlag: Berlin-Heidelberg: A Springer Company.

Hosking, A., \& Western, M. (2008). The effects of non-standard employment on work-family conflict, Journal of Sociology, 44(1), 5-27.

Kossek, E., Valcour, M., \& Lino, P.. (2014). The sustainable workforce: Organizational strategies for promoting work-life balance and well-being. In P. Chen and C. Cooper. (Eds.). Work and wellbeing: A Complete Reference Guide, III. Oxford, UK: Wiley-Blackwell.

McDonald, P., Bradley, L., \&amp; Brown, K. (2009). 'Full-time is a given here': Part-time versus fulltime job quality, British Journal of Management, 20(2), 143-157.

Pfeffer, J. (2010). Building sustainable organizations: The human factor. Academy of Management Perspective, 24(1), 34-45.

Prottas, D.J., Thompson, C.A., Kopelman R.E., \& Jahn, E.W. (2007). Work-family programs: Factors affecting employee knowledge and accuracy. Pers Rev., 36(2), 163-189.

Ruderman, M.N., Ohlott, P.J., Panzer, K. \& King, S.N. (2002). Benefits of multiple roles for managerial women. Academy of Management Journal, 45(2), 369-386. 